\title{
Avaliação de forrageiras tropicais: Revisão
}

$\underline{\text { Gonçalo Mesquita da Silva }}{ }^{*}$; Fabiano Ferreira da Silva $^{2}$; Pablo Teixeira Viana ${ }^{1}$; Eli Santana $\underline{\text { de Oliveira Rodrigues }}^{1}$; Charles Neris Moreira ${ }^{3}$; Murilo de Almeida Meneses ${ }^{1}$; José de Souza $\underline{\text { Abreu Júnior }}^{3}$; Cassyo de Araújo Rufino ${ }^{3}$; Luan da Silva Barreto ${ }^{4}$

${ }^{I}$ Doutorando em Zootecnia na Universidade Estadual do Sudoeste Bahia

${ }^{2}$ Professor da Universidade Estadual do Sudoeste da Bahia - Campus Itapetinga-BA

${ }^{3}$ Professor da Faculdade Guanambi - Campus Guanambi - BA

${ }^{4}$ Aluno de Graduação em Zootecnia na Universidade Estadual do Sudoeste da Bahia

*Autor para correspondência, E-mail:gon_zootecnia23@hotmail.com

RESUMO. A forragem é todo alimento consumido pelos animais (gramíneas e leguminosas), sendo o componente mais importante na dieta dos ruminantes, é a através da ingestão de matéria seca da forrageira que os nutrientes essenciais, carboidratos, proteínas, lipídios, vitaminas e minerais, são metabolizados no trato gástrico intestinal e absorvidos para corrente sanguínea através de mecanismos químicos e fisiológicos ao nível do sistema digestório dos ruminantes. Desta forma, é necessário adotar nas propriedades destinadas a produção animal o manejo de pastagem, pois é através da ingestão de matéria seca do pasto, que os animais conseguem maximizar o seu desempenho produtivo e reprodutivo. Pastagens mal manejadas não fornecem nutrientes em quantidade e qualidade durante todo ano para os animais. Os métodos mais utilizados sobre o sistema de pastejo dos animais são: Pastejo intermitente, pastejo em faixa, pastejo diferido e pastejo limite. Portanto, objetivou-se abordar os diversos métodos utilizados em nível de pesquisa e extensão, através de mensurações de produção de matéria seca das forrageiras tropicais.

Palavras chave:Disponibilidade, fibra em detergente neutro, matéria seca

\section{Tropical forage evaluation: Review}

\begin{abstract}
The forage is all food consumed by animals (grasses and legumes), the most important component in the diet of ruminants, is through the ingestion of dry matter forage that essential nutrients, carbohydrates, proteins, lipids, vitamins and minerals, are metabolized in the gastric intestinal tract and absorbed into the bloodstream through chemical and physiological mechanisms at the level of the digestive system of ruminants. Thus, it is necessary to adopt the properties for animal production management of pasture, it is through dry matter intake pasture, the animals can maximize their productive and reproductive performance. Poorly managed pastures do not provide nutrients in quantity and quality throughout the year for the animals. The methods used for the grazing system are: intermittent grazing, strip grazing, deferred grazing and grazing limit. Therefore, aimed to address the different methods used at the level of research and extension through production of dry matter measurements of tropical forages.
\end{abstract}

Keywords: Availability, neutral detergent fiber, dry matter

\section{Introdução}

O Brasil é um país de grandes extensões de áreas, formadas por forrageiras tropicais. Embora apresente um potencial produtivo em determinada época do ano, ocorre um déficit na produção destas forrageiras durante o período seco. O período das águas compreende a época que concentra os maiores volumes de precipitação iniciando entre os meses de Outubro a Março em praticamente todas as regiões do país, neste período as condições climáticas dentre elas umidade e temperatura são favoráveis e promovem o crescimento e desenvolvimento das forrageiras tropicais, possibilitando uma oferta de 
matéria seca (MS) em abundância para os animais.

A criação dos ruminantes é baseada em sistema de pastagens (gramíneas e leguminosas), sendo economicamente a fonte alimentar mais viável em um sistema produtivo, pois seu custo é relativamente barato em comparação às fontes alimentares tradicionais dentre elas milho, soja e sorgo sendo que estes compõem grande parte da dieta dos animais criados em sistema intensivo.

Uma tendência observada nos anos 70 até os dias atuais é uma redução na área de pastagens naturais e cultivadas em relação às áreas destinadas a agricultura (Mota, 2013).

Os fatores climáticos supracitados permitem neste período chuvoso alcançar o máximo do seu potencial produtivo, chegando a atingir 75 a $90 \%$ de sua capacidade produtiva (Coneglian, 2010). No entanto, devido a manejos inadequados, podem ocasionar redução na produção das forrageiras, tanto no potencial produtivo representado por crescimento dos tecidos vegetativos como no potencial qualitativo (carboidratos estruturais, proteínas e carboidratos solúveis).

Os animais criados em sistema extensivo em determinada época do ano são acometidos por deficiência nutricional em função do baixo consumo de matéria seca (MS) do pasto, em decorrência do aumento e enrijecimento do conteúdo da parede celular (lignina), o que pode ocasionar um baixo desempenho dos animais.

Em sistemas tradicionais de criação de bovinos, o Brasil apresenta uma média produtiva de 3,5 arrobas de carne por hectare ano, sendo uma potência no cenário da pecuária por apresentar o maior rebanho comercial do mundo. No entanto, quanto ao índice de produção de carne, os Estados Unidos assumem o ranking com aproximadamente 11,2 milhões equivalente de carcaça referente ao ano de 2012 (Nogueira, 2014).

Estes resultados são encontrados em função do manejo alimentar utilizado (sistemas de semi confinamento e confinamento) o que permite a terminação de animais mais precoces. Uma das estratégias para aumentar a produção dos produtos de origem animal, dentre elas, leite e carne é através da utilização de técnicas de manejo de pastagens, que permitem oferecer alimento em quantidade e qualidade para os animais durante todo o ano, admitindo assim a maximização no desempenho animal.

Portanto, objetivou-se abordar os diversos métodos utilizados em nível de pesquisa e extensão, através de mensurações de produção de matéria seca das forrageiras tropicais.

\section{Produção da forragem}

A forragem é todo alimento consumido pelos animais (gramíneas e leguminosas), sendo o componente mais importante na dieta dos ruminantes, é a através da ingestão de (MS) da forrageira que os nutrientes essenciais (carboidratos, proteínas, lipídios, vitaminas e minerais), são metabolizados no trato gástrico intestinal e absorvidos para corrente sanguínea através de mecanismos químicos e fisiológicos ao nível do sistema digestório dos ruminantes. Promovendo ao animal, substrato que atenda as necessidades de mantença, produção e reprodução.

A maior parte dessas forrageiras é consumida pelos animais na forma in natura, pelo comportamento natural de pastejo sendo no período chuvoso, aonde ocorre uma produção elevada de massa verde através do desenvolvimento e crescimento vegetativo das plantas forrageiras, parte desse material, pode ser colhido e armazenado na forma de feno e silagem, para serem ofertado aos animais no período de escassez de alimentos (período da seca).

O feno é a forrageira que pode ser (gramíneas ou leguminosas) mediante a desidratação através da perda de água, contudo permanecem os constituintes celulares, de modo a garantir o valor nutricional, permitindo assim seu armazenamento por longos períodos sem serem estragados. Esse processo resume-se na conservação do valor nutritivo da forragem através da rápida desidratação, uma vez que a atividade respiratória das plantas, bem como a dos microrganismos é paralisada.

Assim, a qualidade do feno está associada a fatores relacionados com as plantas que serão fenadas, às condições climáticas durante a secagem e o sistema de armazenamento empregado (Reis et al., 2001).

A silagem é o produto da ensilagem, o qual a forrageira sofreu fermentação láctica da matéria vegetal, durante este processo são produzidos ácidos láticos e outros ácidos orgânicos, 
acarretando diminuição do $\mathrm{pH}$ até valores inferiores a 5, e a criação de anaerobiose. Esse processo interrompe a degradação da matéria orgânica e dessa forma, fica conservada, retendo as qualidades nutritivas do material original.

Conforme Pereira (2001), o processo da ensilagem tem como principio a conservação de forragem cujo procedimento consiste em cortar a forragem, colocá-la no silo, compactá-la e fazer a vedação do silo para que ocorra uma fermentação, sem a presença do oxigênio, com objetivo de conservar o valor nutritivo. Pelo comportamento natural, os animais buscam capturar o alimento pelo ato do pastejo, os bovinos apresentam particularidades e para que aconteça um consumo eficiente de MS, é necessário conhecer o hábito alimentar desta espécie.

Dessa forma, há a necessidade de levar em consideração o crescimento vegetativo da forrageira que será utilizada como fonte alimentar para os bovinos, pois estes, no ato do consumo utilizam a língua e os dentes incisivos inferiores, para capturar a forrageira e assim a pastagem manejada com valores inferiores a 20 $\mathrm{cm}$ em relação ao solo, que pode vir a comprometer o desempenho dos animais pela ineficiência na ingestão.

\section{Manejo de pastagens}

É necessário adotar nas propriedades destinadas a produção animal o manejo de pastagem, sendo que estas constitui a principal fonte alimentar dos ruminantes, sendo através da ingestão de MS do pasto, que os animais conseguem maximizar o seu desempenho produtivo e reprodutivo. As pastagens mal manejadas não fornecem nutrientes em quantidade e qualidade durante todo ano para os animais. Dessa forma, a produção de bovinos depende fundamentalmente da produção de forragem, uma vez que o sistema de pastejo predomina na atividade pecuária (Koscheck et al., 2011).

Nas propriedades com grandes extensões de áreas, o manejo do pasto é comprometido, devido à dificuldade de mão de obra disponível para estimar a produção de MS do pasto, ocorrendo perdas do material pela ineficiência do uso na alimentação dos animais. As forrageiras atingem seu potencial de crescimento e a eficiência da utilização é reduzida, possibilitando o sub pastejo total ou parcial durante o decorrer do ano.
Em contra partida, as propriedades de menores extensões, muitas vezes, são alocados com elevada carga animal e o efeito sobre o consumo de MS da forrageira é muito intenso, proporcionando o superpastejo. Tanto o sub ou superpastejo não é indicado para o melhor aproveitamento da pastagem

O sub pastejo se realiza a uma baixa pressão, o que permite elevada seleção da dieta pelo animal, mas devido ao acúmulo de forragem, grande parte dessa forragem é perdida. Ou seja, é o pastejo numa intensidade bem inferior à capacidade de suporte da pastagem.

O super pastejo caracteriza-se pelo pastejo intensivo e frequente das pastagens, acarretando danos à vegetação, com possíveis perdas de espécies forrageiras. Ou seja, pastejo numa intensidade acima da capacidade de suporte da pastagem.

Desta forma, se recomenda, uma estratégia de aproveitamento dessa forrageira como fonte alimentar para os animais durante todo o ano. Pois, as forrageiras no período de entressafra reduzem sua produtividade ocorrendo diminuição do valor nutricional, sendo a suplementação uma estratégia para corrigir as deficiências do pasto.

Deste modo, o manejo da pastagem é baseado em três características básicas: intensidade, frequência e seletividade consistiram na combinação definida e integrada do animal, da planta, do solo e de outros componentes do ambiente e quando estes se encontram em desequilíbrio, o resultado pode ser comprometido.

\section{Métodos de pastejo}

Os métodos mais utilizados sobre o sistema de pastejo dos animais são: Pastejo intermitente, pastejo em faixa, pastejo diferido e pastejo limite. Todos estes, são manejados para atingir resultados ou objetivos específicos permitindo maior ingestão de MS pelos animais.

Pastejo intermitente (Lotação rotativa) método de pastejo que usa períodos recorrentes de descanso e de pastejo entre duas ou mais subdivisões (piquetes) numa pastagem durante a estação de pastejo.

Pastejo em faixas - Quando se trabalha com vacas de leite, é interessante, quando possível realizar o pastejo em faixas, pois, consiste na redução do período de pastejo para apenas um dia, de modo a garantir uniformidade na 
produção diária de leite, já que a qualidade da dieta ingerida pelas vacas em lactação não modificará de um dia para o outro neste método, não permite que os animais pastejem na parcela seguinte de pastejo. Comumente utiliza cercas elétricas móveis, acoplado a um trator e segue a faixa determinada para o pastejo, sendo usados principalmente sobre manejo de pivô central.

Pastejo diferido - Ocorre quando o piquete na lotação rotativa ao final da estação das chuvas é "vedado" para posterior utilização na época da seca permitindo a revigoração natural dos pastos. Esta prática deve ser aplicada de forma alternada nas áreas de pastagens, com intervalos de 2 a 3 anos. Rodrigues (1997) cita uma das vantagens do pastejo diferido é o fato de dispensar investimento em máquinas utilizadas na conservação de forragem. Já Maraschin (1986) salientam que a eficiência do pastejo diferido está estreitamente associada com a qualidade da planta forrageira na área diferida teria na ocasião a ser consumida.

Pastejo Limite (Lotação contínua) - Método de pastejo em que o rebanho tem acesso irrestrito e ininterrupto a toda à pastagem, durante toda a estação de pastejo Silva (1996). Este manejo é que mais se encontra nas propriedades brasileiras, pois é o extensivo convencional, pouco semtecnificação apenas, roçagem, reforma de cerca e aplicação de herbicida em situação restrita.

\section{Avaliação das forrageiras}

A determinação da disponibilidade de forragem em pastagem é de fundamental importância, tanto para a pesquisa científica quanto para o planejamento da exploração racional de áreas manejadas comercialmente (Carvalho et al., 2008).

As forrageiras em sistema extensivo são cultivadas em grandes áreas o que dificulta a estimação correta da quantidade de MS em quilogramas por hectare, comprometendo a utilização correta desse material na alimentação dos ruminantes. Existem técnicas que são aplicadas, para estimar a produção de forragem por área, entre estas, estão às técnicas diretas e as indiretas, o uso de um desses métodos proporciona uma estimativa próxima do real.

\section{Avaliação das forrageiras com animais}

\section{Técnicas diretas}

Conhecida como o método do quadrado, esta tem sido mais usada, pois, é de uma estrutura simples, através de molduras de ferro ou madeira que pode ser usado da própria propriedade podem ser dimensionadas no formato de um retângulo ou de um quadrado, a área a ser estabelecida será em função da forrageira que será avaliada. A área das molduras varia de $0,10 \mathrm{~m}^{2}$ até $2,0 \mathrm{~m}^{2}$.

O tamanho do quadrado a ser utilizado depende da uniformidade da área a serem amostrada, para as gramíneas de crescimento uniforme, como exemplo, as espécies de Brachiarias sendo recomendada área de $0,5 \times 0,5$ $\mathrm{m}\left(0,25 \mathrm{~m}^{2}\right)$, e quadrados maiores $(1,0 \times 1,0 \mathrm{~m})$ são recomendadas quando as pastagens são muito heterogêneas, devido a presença de áreas descobertas e, ou devido a diversidade de espécies de plantas, no caso de uma área de pastagem natural ou em estágio de degradação sendo forrageiras que formam torceras como exemplo é o crescimento dos Panicum (Costa et al., 2009).

Desse modo, a área da moldura será em função do crescimento das forrageiras $e$ capacidade de formação da mesma. Na tabela 1 estão apresentados diferentes formatos de moldura que melhor se adeque para as espécies distintas.

Tabela 1- Medidas de quadrado para a medição da produção de pastagem (técnica direta).

\begin{tabular}{|c|c|c|c|}
\hline Forrageiras & $\begin{array}{l}\text { Hábito de } \\
\text { crescimento }\end{array}$ & $\begin{array}{l}\text { Dimensões de molduras } \\
(\mathrm{m})\end{array}$ & $\begin{array}{l}\text { Área da moldura } \\
\qquad\left(\mathrm{m}^{2}\right)\end{array}$ \\
\hline Coast-cross, Tiftons, Estrela & Prostrado, rasteiro & $0,5 \times 0,5$ ou $0,5 \times 1,0$ & 0,25 ou 0,5 \\
\hline $\begin{array}{l}\text { Pangola, Braquiarão, Xaraés, Braquiária } \\
\text { decumbens }\end{array}$ & $\begin{array}{l}\text { Prostrado, } \\
\text { subprostrado }\end{array}$ & $1,0 \times 1,0$ ou $0,5 \times 2,0$ & 1,0 \\
\hline $\begin{array}{l}\text { Mombaça, Tanzânia, Andropogon, } \\
\text { Capim Elefante }\end{array}$ & Ereto, touceira & $1,5 \times 1,5$ ou $1,0 \times 2,25$ & 2,25 \\
\hline
\end{tabular}

Fonte:http://www.prodap.com.br. 
Após estabelecer a área para avaliação da forrageira é jogada a moldura "quadrado" aleatoriamente em pontos ao acaso em média 40 quadrados por hectare, em tabelas específicas serão anotadas os valores onde o quadrado caiu e relacione a forrageira com escores pré-definidos antes da aplicação do método. Coleta uma quantidade de amostra de que posam servir de base para estabelecer a produção de MS por hectare e parte desse material serãocoletados e separados os constituintes (composta, folha, colmo e material morto) que serão secos em estufa de $65^{\circ}$ por 72 horas para posteriores análises químicas (Silva \& Queiroz, 2002).

Outra técnica do corte que é muito usada em sistemas de pastejo contínuo é o uso de gaiolas de exclusão (Hodgson et al., 2000). Segundo autores, a limitação desta técnica está no fato de não haver a influência da distribuição de urina e fezes pela pastagem e os efeitos do pisoteio dos animais e do hábito de pastejo seletivo.

Esta técnica acarreta um ambiente diferente daquele onde os animais pastejam, a gaiola limita o consumo dos animais e o crescimento da forrageira é contínuo desde que os fatores climáticos e ambientais sejam favoráveis. Este método de coleta é através de corte da forrageira, semelhante ao da técnica do quadrado (Carvalho et al,. 2008).

Pastejo Simulado - Esta técnica é baseada na coleta de amostras da forragem no qual o animal estar pastejando, são observados o comportamento do animal no ato da captura da forrageira, conforme Johnson (1978). Identificando-se o tipo de material consumido e coletando-se uma amostra semelhante ao alimento ingerido respeitando os processos seletivos dos animais.

\section{Avaliação da forrageira sem animais}

\section{Técnicas indiretas}

Está técnica têm sido usados com o objetivo de amenizar as desvantagens do uso do método direto para avaliação de grandes áreas de pastagens. Diversos estudos vêm buscando o aprimoramento de métodos indiretos, não destrutivos, para viabilizar uma avaliação rápida, menos trabalhosa e custo reduzido.

Entretanto, esses métodos têm a desvantagem da relação usada não ser uma função linear, por exemplo, entre altura e produção de matéria seca que diferem grandemente entre espécies, tipo de hábito de crescimento, altura, estágio de crescimento, entre outros. Estes são considerados menos precisos que os métodos diretos, pois as técnicas diretas são usadas através do corte da forrageira e as mensurações são mais confiáveis. Dentre os métodos indiretos, os mais conhecidos são: Altura do dossel, estimativa visual, disco medidor e sondas eletromagnéticas Silva \& Cunha, (2003).

\section{Altura do dossel}

A relação direta entre a altura do dossel e a produção de forragem não fornece estimativas confiáveis de disponibilidade. Porém, a medida da altura do capim tomada com uma régua vem sendo bastante praticada para definir quando os animais devem entrar e sair de determinado piquete consultando-se uma tabela que indica a melhor altura de entrada e saída dos animais. Dessa maneira, pode-se adotar um esquema de ocupação da pastagem que proporcione um bom aproveitamento da forragem disponível sem prejudicar o desenvolvimento da planta. A Embrapa desenvolveu uma ferramenta, a régua no ano de 2012, esta é colorida com cores vermelha e verde que são de fácil utilização, os pecuaristas controlam a entrada dos animais na área a ser pastejada em função da altura do dossel. Após o pastejo é avaliados em pontos diferentes a altura de resíduo remanescente, caso a pastagem esteja na altura da coloração vermelha, os animais devem ser mudados de piquetes.

O uso da altura do dossel como medida indireta é, portanto, melhor relacionado com a massa de forragem se a densidade do dossel for uniforme e constante ao longo de todo o perfil. Como isso é improvável, mesmo nos dosséis mais homogêneos, a massa de forragem será não raramente superestimada quanto mais alta for 0 dossel, pois as maiores densidades são frequentemente encontradas nos estratos inferiores, próximo à base da vegetação.

\section{Estimativa visual}

A avaliação visual é estimada em $\mathrm{kg}$ de MS ou massa da forrageira, a utilização dessa técnica estar baseada na produção de MS por meio de escores visual em relação ao peso da forrageira por hectare. É uma pratica rápida não destrutiva e de baixo custo, permitindo avaliar um número grande de amostras (Santos, 1997). 
A dificuldade em estabelecer essa técnica em nível de extensão é devido à alta variabilidade das amostras observadas, resultando em menor precisão do método. Para obtenção de resultados positivos, será necessário um bom treinamento prévio dos avaliadores (Pedreira, 2002).

\section{Disco medidor}

Esse método é baseado na utilização de um disco de alumínio com $900 \mathrm{~cm}^{2}$ com um orifício no centro capaz de movimentar livremente por uma haste graduada de espaçamento entre $0,5 \mathrm{~cm}$ e sua mensuração é realizada com a introdução da ponta da haste no dossel da forrageira no sentido perpendicular, do topo para a base até atingir o solo, e a leitura é realizada da posição do disco na escala da haste com a compressão da forrageira (Salman et al., 2006).

As forrageiras que melhor adapta a esta técnica, são as forrageira de baixo e médio porte, as de espécies de folhas e colmos macios é uma técnica de fácil utilização e que necessita ser avaliada em diversos pontos na área da pastagem, com o objetivo de fornecer dados confiáveis. O disco pode ser suavemente colocado na forrageira com uma leve pressão sobre o material, após o procedimento, a forrageira que estar entre o disco e o solo, é mensurado com o auxílio da haste graduada e os valores observados serão anotados em tabelas especificas (Carvalho et al., 2008). E através de análises de regressão, será determinada a relação estabelecida entre a produção de MS e a altura do disco, a calibração do aparelho é feito com um arco de metal com o mesmo diâmetro do disco, sendo colocado sobre o solo e a forrageira dentro do arco é cortada, pesada e seca em estufas de ventilação forçada, determinada a concentração de MS e as mostras seguirão para serem analisadas quimicamente de acordo (Silva\& Queiroz, 2002).

\section{Sondas eletromagnéticas}

É uma das técnicas utilizadas com maior frequência em outros países, principalmente os de climas temperados onde as forrageiras existentes apresentam elevadas concentrações de água na sua constituição. A mensuração é tomada através de capacitância elétricas das forrageiras, foi desenvolvida na década de 60 e a mais de 50 anos são utilizadas.

A eficiência do método é baseada na concentração de umidade da planta, sendo necessárias várias calibrações (Pedreira, 2002).
As forrageiras tropicais apresentam baixa eficiência quando são avaliadas por esta técnica, por ser muito subjetiva.

Atualmente tem-se desenvolvido equipamentos avançados, capaz de permitir monitorar, por meio de do fluxo de radiação na cobertura vegetal, o momento adequado à colheita eficiente das forrageiras. $\mathrm{O}$ equipamento conhecido como Sistema de Análise de Dossel (Sun Scan) da DeltaTDevices - UK. É um dos aparelhos mais modernos a nível internacional e que possibilita determinar o manejo correto das forrageiras nos sistemas silvipastoris e os sistemas convencionais de pastagens sem ter que retirar os animais da área pastejada.

Os múltiplos parâmetros registrados com o equipamento podem ser associados a parâmetros técnicos de uso mais difundido entre produtores possibilitando um manejo mais sustentável das pastagens e assim, ter o melhor controle da carga animal na área.

O equipamento foi adquirido no ano de 2013 por meio de recursos do CNPq e será utilizado em pesquisas de campo, a equipe responsável são os pesquisadores do setor de bovinocultura e pastagem da Universidade Federal do Paraná UFPR.

\section{Considerações Finais}

Estimar a produção das forrageiras nas propriedades é interessante, por nortear os pecuaristas em empregar racionalmente o método adequado a ser utilizado nas pastagens, durante todo ano para não ocasionar a deficiência alimentar dos animais.

Os métodos descritos nesta revisão de literatura não trazem $100 \%$ de eficiência na avaliação quantitativa das forrageiras, mais podem optar por aquele que se ajuste melhor a realidade da propriedade.

\section{Referências Bibliográficas}

Carvalho, R. C. R.; Athayde; A. A. R.; Valeriano; A. R., Medeiros, L. T., Pinto, J. C. (2008). Método de determinação da disponibilidade de forragem. Ciência et Praxis, 1, 7-10.

Coneglian, S. (2014). Suplementação de verão Desperdício ou benefício? Disponível em: $<$ http://www.nftalliance.com.br/suplementaca o-de-verao/> Acesso em abril. 
Costa; N. L.; Gianluppi; V.; Bendahan; A. B et al. (2009). Fisiologia e Manejo de Gramíneas Forrageiras Tropicais. ISSN 1981 - 6103 Junho, EMBRAPA.

Hodgson, J., Matthew, C., Harrington, K. C. Pasture measurement. (2000). In: Hodgson, J.; White, J.; ed. New Zealand: pasture and crop science. Auckland, New Zealand: OXFORD, 59-66.

Johnson, A.D. (1978). Sample preparation and chemical analysis of vegetation. In: Manetje, L.T. (Ed.) Measurement of grassland vegetation and animal production. Aberustwyth: Commonwealth Agricultural Bureaux. 96-102.

Koschecr; J. F. W.; Zevoudaris; J. T.; Carvalho; D. M. G. et al., (2011). Suplementação de bovinos de corte em sistema de pastejo. UNI. Ciências, 15:1.

Maraschin, G. E. (1996). Produção de carne a pasto. In: Simpósio Sobre Manejo De Pastagens, 13, Piracicaba. Anais. Piracicaba: FEALQ, 1997. p. 243-276. Mota, C. Pecuária brasileira reduz área e dobra produção em 36 anos.

Neto; A. F. G. Manejo de forrageiras na UFPR Palotina passa a ser monitorado com o sistema de análise de cobertura do dossel. Disponível em: < http://lnavet.blogspot.com.br/2013/08/manejo-deforrageiras-na-ufpr-palotina.html/> Acesso em: maio, 2014.

Nogueira; M. P. Pastagem, a cultura esquecida. Disponível em: < $\quad<$ http://www.rallydapecuaria.com.br/2014/?p=1 06/> Acesso em abril2014.

Pedreira, C. G. S. (2002) Avanços metodológicos na avaliação de pastagens. In: Reunião Anual da Sociedade Brasileira de Zootecnia, Recife, 2002. Anais de Palestra. Recife: SBZ.

Pereira; J. R. A.; Reis; R. A. (2001). Produção de silagem pré-secada com forrageiras temperadas e tropicais. In: Simpósio Sobre Produção e Utilização de Forragens Conservadas, Maringá. Anais. Maringá: Universidade Estadual de Maringá, p.64-86.

Reis, R. A.; Moreira; A. L. \& Pedreira; M. S. (2001). Técnicas para produção e conservação de fenos de forrageiras de alta qualidade. In: Simpósio Sobre Produção e Utilização de
Forragens Conservadas. Anais do Simpósio Sobre Produção e Utilização de Forragens Conservadas. Jobim, C. C.; Cecato, U; Damasceno, J. C.; Santos, G. T. (eds) Maringá : UEM/CCA/DZO, 319 P.

Rodrigues, L. R. A. \& Reis, R. A. (1997). Conceituação e modalidades de sistemas intensivos de pastejo rotacionado. In: Simpósio Sobre Manejo de Pastagens, 14, Piracicaba, Anais. Piracicaba: FEALQ, 1997. $1-24$.

Salman; A. K. D.; Soares; J. P. G. \& Canesin. R. C. (2006). Métodos de amostragem para avaliação quantitativa de pastagens. ISSN 0103-9334. Circular Técnica..

Santos, M.V.F. (1997). Métodos agronômicos para estimativa de consumo e de disponibilidade de forragem na Zona da Mata Viçosa, 155p. Tese (Doutorado)Universidade Federal de Viçosa.

Silva, D. J. \& Queiroz, A. C. (2002). Análises de alimentos (Métodos químicos e biológicos). 3. ed. Viçosa, MG: Editora UFV, 235p.

Silva C. \& Cunha, W. F. (2003). Métodos indiretos para estimar a massa de forragem em pastos de Cynodon spp. Pesquisa Agropecuária Brasileira, 38, 981-989

Silva, S. C.; Faria, V. P. \& Corsi, M. (1996). Sistema intensivo de produção de leite em pastagens de capim-elefante do Departamento de Zootecnia da Esalq. In:Congresso Brasileiro de Gado Leiteiro, 2, Piracicaba, 1995. Anais Piracicaba: FEALQ, 97-122.

\section{Recebido em Julho 24, 2015}

Aceito em setembro 9, 2015

License information: This is an open-access article distributed under the terms of the Creative Commons Attribution License, which permits unrestricted use, distribution, and reproduction in any medium, provided the original work is properly cited. 